\title{
BCG directly induces cell cycle arrest in human transitional carcinoma cell lines as a consequence of integrin cross-linking Fanghong Chen*1,3, Guangjian Zhang*1,3, Yoshiki Iwamoto ${ }^{1,2}$ and William A See ${ }^{1}$
} \author{
of Wisconsin, Milwaukee, WI, USA and ${ }^{3} \mathrm{Co}$-first authors \\ Email: Fanghong Chen* - fanghongchen@hotmail.com; Guangjian Zhang* - gizhang55@ hotmail.com; \\ Yoshiki Iwamoto - yiwamoto@mail.mcw.edu; William A See - wsee@mail.mcw.edu \\ * Corresponding authors
}

Address: ${ }^{1}$ Department of Urology, Medical College of Wisconsin, Milwaukee, WI, USA, ${ }^{2}$ Human and Molecular Genetics Center, Medical College

Published: 12 May 2005

BMC Urology 2005, 5:8 doi:10.1 186/147/-2490-5-8

This article is available from: http://www.biomedcentral.com/I47/-2490/5/8

(C) 2005 Chen et al; licensee BioMed Central Ltd.

This is an Open Access article distributed under the terms of the Creative Commons Attribution License (http://creativecommons.org/licenses/by/2.0), which permits unrestricted use, distribution, and reproduction in any medium, provided the original work is properly cited.
Received: 08 February 2005

Accepted: 12 May 2005

\begin{abstract}
Background: Current models of the mechanism by which intravesical BCG induces an anti-tumor effect in urothelial carcinoma propose a secondary cellular immune response as principally responsible. Our group has demonstrated that BCG mediated cross-linking of $\alpha 5 \beta$ I integrin receptors present on the tumor surface elicits a complex biologic response involving API and NF$\kappa \mathrm{B}$ signaling as well as the transactivation of immediate early genes. This study evaluated the direct biologic effect of cross-linking $\alpha 5 \beta$ I integrin on cell cycle progression and apoptosis in two human urothelial carcinoma cell lines.
\end{abstract}

Methods: Two independent assays (MTT and Colony forming ability) were employed to measure the effect of $\alpha 5 \beta$ I cross-linking (antibody mediated or BCG) on cellular proliferation. Flow cytometry was employed to measure effect of BCG and $\alpha 5 \beta \mathrm{I}$ antibody mediated cross-linking on cell cycle progression. Apoptosis was measured using assays for both DNA laddering and Caspase 3 activation.

Results: Results demonstrate that integrin cross-linking by BCG, or antibody mediated crosslinking of $\alpha 5 \beta$ I resulted in a decrease in proliferating cell number. BCG treatment or $\alpha 5 \beta$ I cross-linking increased the percentage of cells in G0/GI, in both $253 \mathrm{~J}$ and T24 cell lines. Peptide mediated blockade of integrin binding site using RGDS reversed the effect BCG on both proliferation and cell cycle arrest. Apoptosis in response to BCG was not identified by either DNA laddering or Caspase 3 activation.

Conclusion: These findings show that BCG exerts a direct cytostatic effect on human urothelial carcinoma cell lines. Cell cycle arrest at the GI/S interface is a mechanism by which BCG inhibits cellular proliferation. This effect is duplicated by antibody mediated cross-linking of $\alpha 5 \beta \mathrm{I}$ and likely occurs as a consequence of crosslink-initiated signal transduction to cell cycle regulatory genes. 


\section{Background}

Bacille Calmette Guerin (BCG) remains the most effective available treatment option for non-muscle invasive urothelial carcinoma. Its superiority, both in terms of preventing recurrence and progression, has been demonstrated in multiple studies.[1-3] The mechanism responsible for BCG's superior anti-tumor activity is felt to be principally a consequence of an immune mediated response.[4] Investigators have shown the importance of a cellular immune response in orthotopic animal models of urothelial malignancy. The "effector" cell population responsible for the anti-tumor activity is currently felt to be natural killer (NK) cells.[4]

While an extensive literature supports an immune mechanism as being responsible for a portion of BCG's antitumor activity, a direct effect of BCG has been demonstrated by other authors. Multiple studies have demonstrated an in vitro anti-proliferative effect of BCG against human urothelial carcinoma cell lines. [5,6] Other authors have demonstrated a direct effect of BCG on other important biologic end points such as invasion.[7] The precise mechanism responsible for this direct effect is ill defined.

Work by others together with recent studies by our group has demonstrated that BCG has a direct gene regulatory effect in urothelial carcinoma cell lines. We have shown that this response is mediated via signal transduction initiated as a consequence of BCG induced cross-linking of $\alpha 5 \beta 1$ integrins present on the surface membrane of urothelial carcinoma cells.[8] Activation of signaling through NF- $\mathrm{KB}$ and AP1 initiate the transactivation of immediate early genes including interleukin 6 (IL-6).[9] Given the prevalence of NF- $\mathrm{KB}$ and AP1 response elements in the promoters of genes, it is likely that multiple genes are activated as a consequence of BCG/ $\alpha 5 \beta 1$ crosslinking.

Historically, studies assessing a direct effect of BCG on tumor cells were hampered by the need to add a bacterial preparation to the culture media. In this setting it is difficult to separate a true direct anti-tumor effect of BCG from culture artifact.[6] Changes in $\mathrm{pH}$, byproducts of the BCG preparation, and/or bacterial toxins have the potential to influence experimental outcome and yet fail to represent a relevant in vivo mechanism. The current study employed a non-biologic model that reproduces BCG induced signaling to determine whether BCG exerts a direct anti-tumor effect. Our results show that BCG decreases cell proliferation as measured by two separate assays of cell viability. Cell cycle arrest at the G1/S interface, rather than apoptosis, appears to be the mechanism by which this response occurs. These results are reproduced by the non-biologic signaling model in which $\alpha 5 \beta 1$ integrin receptors are cross-linked via antibodies and blocked by peptide fragments that inhibit the ability of fibronectin (FN) to function as a bridge for BCG mediated cross linking of these receptors.

\section{Methods \\ Cell lines}

The human transitional carcinoma cell lines 253J and T24 were obtained from American Type Cell Culture (Rockville, MD). Cells were maintained at $37^{\circ} \mathrm{C}, 5 \% \mathrm{CO}_{2}$ in RPMI 1640 (Gibco BRL, Grand Island, NY) supplemented with $10 \%$ fetal bovine serum (FBS), penicillin, and streptomycin (complete media).

\section{Bacillus Calmette-Guerin (BCG)}

TICE BCG, living organisms of an attenuated, Bacillus of Calmette and Guerin strain of Mycobacterium bovis were used in the experiments (Organon Inc, West Orange, NJ). Freeze dried BCG was reconstituted in complete media at an estimated concentration of $2.5 \times 10^{7}$ viable organisms/ $\mathrm{ml}$. (dilution assumed average viability of $4 \times 10^{8}$ organisms per vial based upon manufacturer's specified range of 1 to $8 \times 10^{8}$ per vial)

\section{Antibody mediated cross-linking}

Antibody mediated cross-linking of $\alpha 5 \beta 1$ integrin was carried out as previously described.[8] Briefly, the following mouse mAbs were used: anti- $\alpha 5$ and anti- $\beta 1$ Abs were purchased from Santa Cruz Biotechnology (Santa Cruz, $\mathrm{CA}$ ). Affinity-purified $\mathrm{F}\left(\mathrm{ab}^{\prime}\right)_{2}$ goat anti-mouse (GAM) antibody was purchased form BioSource International. Cells were resuspended in 10\% FBS RPMI-1640 and cultured at $37^{\circ} \mathrm{C}$ for $45 \mathrm{~min}$ after trypsinization, then resuspended in RPMI-1640 serum-free medium $\left(4 \times 10^{7}\right.$ cells/

$300 \mu \mathrm{l} /$ tube) and incubated with anti- $\alpha_{5}$ or anti- $\beta 1$ integrin $\mathrm{mAb}(5 \mu \mathrm{g} / \mathrm{ml})$ for $30 \mathrm{~min}$ at $4^{\circ} \mathrm{C}$ and washed with cold phosphate buffered saline (PBS). To initiate receptor cross-linking, $F\left(a^{\prime}\right)_{2}$ goat anti-mouse $F\left(a b^{\prime}\right)_{2} A b$ $(100 \mu \mathrm{g} / \mathrm{ml})$ was added after warming the cells to $37 \mathrm{C}$ in RPMI-1640 medium Cells were incubated at 37C. Cells were harvested by pelleting the cells for $5 \mathrm{~min}$ at $500 \times \mathrm{g}$.

\section{Cell viability assay (MTT)}

For the determination of the cell viability, we estimated cellular bioreduction of 3-(4,5-dimethylthiazol-2-yl)-2,5diphenyl tetrazolium bromide (MTT) subsequent to cell exposure to either BCG or antibody mediated $\alpha 5 \beta 1$ crosslinking.[10] A $200 \mu \mathrm{l}$ volume of an exponentially growing cell suspension $\left(1 \times 10^{4}\right.$ cells $\left./ \mathrm{ml}\right)$ was seeded into a 96well microtiter plate. Twenty-four hours later $20 \mu \mathrm{l}$ of BCG at a ratio of 50:1 BCG to cells was added. After incubation for $1,2,3$, or 6 days at $37^{\circ} \mathrm{C}, 20 \mu$ l of MTT solution $(5 \mathrm{mg} / \mathrm{ml}$ in phosphate buffered saline, PBS) was added to each well and the plates were incubated for a further $2 \mathrm{hr}$ at $37^{\circ} \mathrm{C} .200 \mu \mathrm{l}$ of lysis buffer (20\% SDS in $50 \% \mathrm{DMF}$ ) 
was added to each well and cells were continuously incubated for a further $2 \mathrm{hr}$ at $37^{\circ} \mathrm{C}$. Optical density was measured at $570 \mathrm{~nm}$. Each experiment was performed in 3 replicate wells for each treatment and carried out independently a minimum of 3 times.

\section{Colony forming assay}

Colony outgrowth of human urothelial carcinoma cells following exposure to BCG or antibody mediated crosslinking of $\alpha 5 \beta 1$ was measured using a colony forming assay. $1 \times 10^{5}$ of 253 J or T24 cells were seed in 48-well plate with 1640 medium plus 10\% FBS. After 24 hours cells were treated with $1 \times 10^{7}$ BCG. After 1, 2, 3, or 6 days incubation, the cells were trypsinized with $0.1 \mathrm{ml}$ of Trypsin-EDTA per well. Trypsinized cells were resuspended in a $10 \mathrm{ml}$ total volume of minimal essential medium (MEM) plus 20\%FBS. $0.2 \mathrm{ml}$ of this cell suspension was transferred into MEM plus 5\%FBS at total volume of $25 \mathrm{ml}$. Five $\mathrm{ml}$ of this final cell suspension was seeded onto grid marked $60 \mathrm{~mm}$ culture plate with grid. Three plates were included for each group. The cells were incubated at $37^{\circ} \mathrm{C}$. After 7 days of incubation, $0.5 \mathrm{ml}$ of 2.5\% glutaraldehyde (Sigma, St. Louis, MO) was directly added to each plate. The plates were incubated at room temperature for $45 \mathrm{~min}$. The media and glutaraldehyde was aspirated and $1 \mathrm{ml}$ of Wright-Giesma solution (EM Science, Gibbstown, NJ) added for 30 minutes to stain the colonies. One $\mathrm{ml}$ of Buffer Solution (LabChem Inc, Pittsburgh, PA) was added and the plates incubated at room temperature for an additional $30 \mathrm{~min}$. The plates were gently rinsed under flowing tap water. After drying, the colonies were manually counted under magnification. For assay purposes, colonies were defined as consisting of 20 or more cells. For experiments employing antibody mediated cross-linking of $\alpha 5$ integrin, $1 \times 10^{5}$ of 253J or T24 cells were cultured in 48 -well plate with 1640 plus $10 \%$ FBS at $37^{\circ} \mathrm{C}$. After 24 hours, the media was changed to medium containing $5 \mu \mathrm{g} / \mathrm{ml}$ mouse monoclonal $\alpha 5$ antibody. The cells were incubated at $4^{\circ} \mathrm{C}$ for $45 \mathrm{~min}$ and then washed twice with serum free 1640 medium. Cross linking was achieved by incubating the cells with media containing GAM $(10 \mu \mathrm{g} / \mathrm{ml})$ at $37^{\circ} \mathrm{C}$ for $48 \mathrm{hrs}$. The CFA was performed as described as the above. Untreated cells, cells exposed to only primary antibody, and cells exposed to secondary antibody served as controls.

\section{Flow cytometry}

Flow cytometry was employed to quantify the cell cycle compartmentalization of TCC lines following exposure to BCG or antibody mediated cross-linking of $\alpha 5 \beta 1.5 \times 10^{6}$ cells/per $6 \mathrm{~cm}$ dish were synchronized using serum starvation for 60 hours prior to the start of the experiment. At time zero, cells were exposed to BCG and 10\% fetal bovine serum (FBS) at a ratio of 50:1 BCG to cells or to $10 \%$ FBS alone. After 24 or 48 hours cells were trypsinized, centrifuged at $1500 \mathrm{rpm}$ for $5 \mathrm{~min}$, washed with PBS, and then treated with $50 \mu \mathrm{g} / \mathrm{ml}$ RNase A (Sigma). DNA was stained with $50 \mu \mathrm{g} / \mathrm{ml}$ propidium iodide for $10 \mathrm{~min}$ at room temperature and cell cycle analysis performed.

\section{Apoptosis assay}

Induction of apoptosis in response to BCG exposure or antibody mediated cross-linking of $\alpha 5 \beta 1$ was determined by measuring DNA fragmentation and activation of the Caspase 3 pathway.[11] For DNA fragmentation, $1 \times 10^{6}$ 253J cells in 1640 plus 10\%FBS were seeded in $6 \mathrm{~cm}$ plates. The following day cells were treated with $1 \times 10^{8}$ of BCG for 48 hrs. Non-adherent BCG was washed from the plate and cells harvested in a digestion solution, consisting of $100 \mathrm{mM} \mathrm{NaCL}, 10 \mathrm{mM}$ Tris, $10 \mathrm{mM}$ EDTA, $0.5 \%$ SDS, and $0.1 \mathrm{mg} / \mathrm{ml}$ Proteinase $\mathrm{K}$, pH8.0. After overnight digestion at $50^{\circ} \mathrm{C}$, the cell lysates were extracted with phenol/chloroform and the DNA in the aqueous phase precipitated with ethanol and resuspended in Tris-EDTA buffer. After digestion with $5 \mu \mathrm{g} / \mathrm{ml}$ RNase A for $1 \mathrm{hr}$, DNA was re-precipitated and DNA samples were electrophoretically separated on $1.5 \%$ agarose gel containing ethidium bromide $(0.5 \mu \mathrm{g} / \mathrm{ml})$. DNA was visualized by a UV transilluminator and the gels photographed.

In the caspase 3 assay, 253J cells were seeded at $1 \times 10^{6}$ in $6 \mathrm{~cm}$ plates. The next day cells were treated with BCG at a ratio of 1 to 50 for 6 hours. At intervals following BCG exposure, cells were harvested with trypsinization, washed once in PBS, fixed and permeabilized using the Cytofix/ Cytoperm Kit (BD Biosciences) for $20 \mathrm{~min}$ at room temperature (RT), pelleted and washed with Perm/Wash buffer. Cells were then stained with anti-active caspase-3 $\mathrm{mAb}$ using $20 \mathrm{ug} / 1 \times 10^{6}$ cells for $60 \mathrm{~min}$ at room temperature in the dark. Following incubation with the Ab, cells were washed in Perm/Wash Buffer and analyzed by flow cytometry.

All experiments were performed in triplicate. Results are shown as the average value +/- one standard error.

\section{Results \\ BCG inhibits urothelial carcinoma cell proliferation}

Figures 1 and 2 demonstrate the effect of BCG exposure on the viability of the human urothelial carcinoma cell lines 253J and T24 as measured by the MTT and CF assays respectively. Both cell lines, in both assays, demonstrated a decrease in cell viability. Three days following BCG exposure, the viability of 253J and T24 cells was $41 \%$ and $58 \%$ of control values in the MTT assay. In the CF assay, colony counts were decreased in the 253J and T24 cells to $27 \%$ and $24 \%$ respectively of control values after 3 days of exposure. 


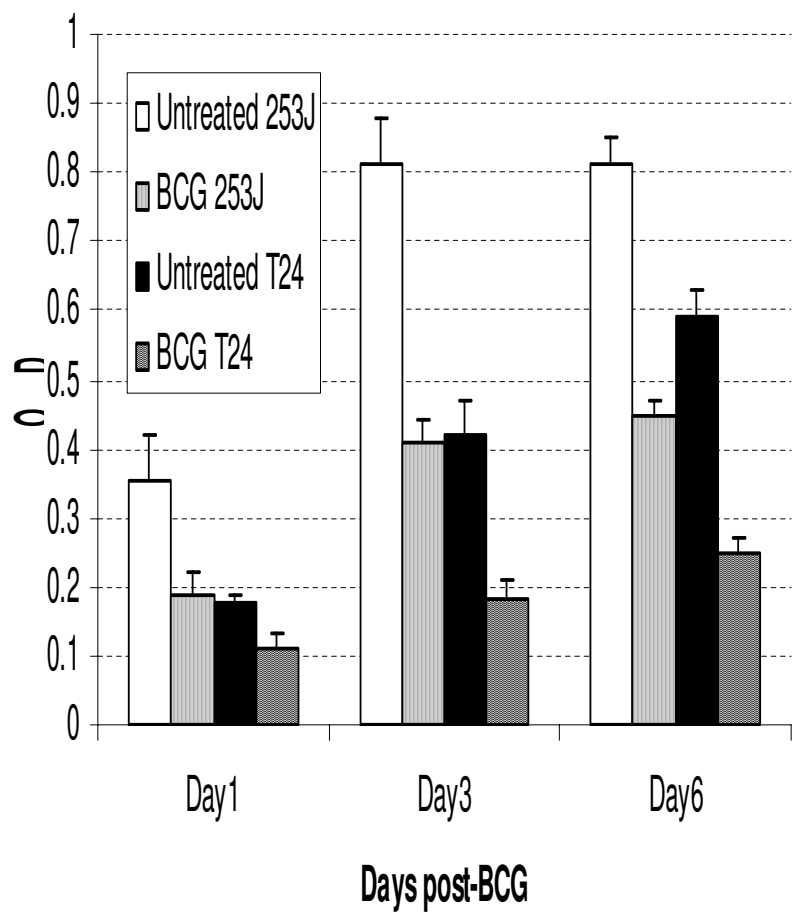

Figure I

BCG decreases the proliferation of human urothelial carcinoma cell lines as measured by the MTT assay. Exposure of either 253 J or T24 cells to BCG resulted in a decrease in viable cell number as measured by the optical density of the metabolic product. The day represents the duration of exposure to $B C G$

\section{Antibody mediated cross-linking of $\alpha 5 \beta$ I integrin inhibits urothelial carcinoma cell proliferation}

Figures 3 and 4 demonstrate the effect of antibody mediated $\alpha 5 \beta 1$ cross-linking on the viability of the human urothelial carcinoma cell lines 253J and T24 as measured by the MTT and CF assays respectively. Cross-linking decreased viability as measured by the MTT assay to $78 \%$ and $77 \%$ of untreated controls in the 253J and T24 lines at 3 days. Colony forming ability was similarly decreased in both cell lines with the average colony count reduced to $23 \%$ and $42 \%$ of untreated controls in the respective cell lines.

\section{BCG induces cell cycle arrest at the GI/S interface}

Figure 5 demonstrates the effect of BCG exposure on cell cycle compartmentalization in 253J and T24 cells. Following BCG exposure, the percentage of cells in G0/G1 increased $40 \%$ and $75 \%$ in the respective cell lines. The increase in $\mathrm{G}$ phase population was mirrored by a decrease in the percent of cells in $S$ phase. The $S$ phase cell

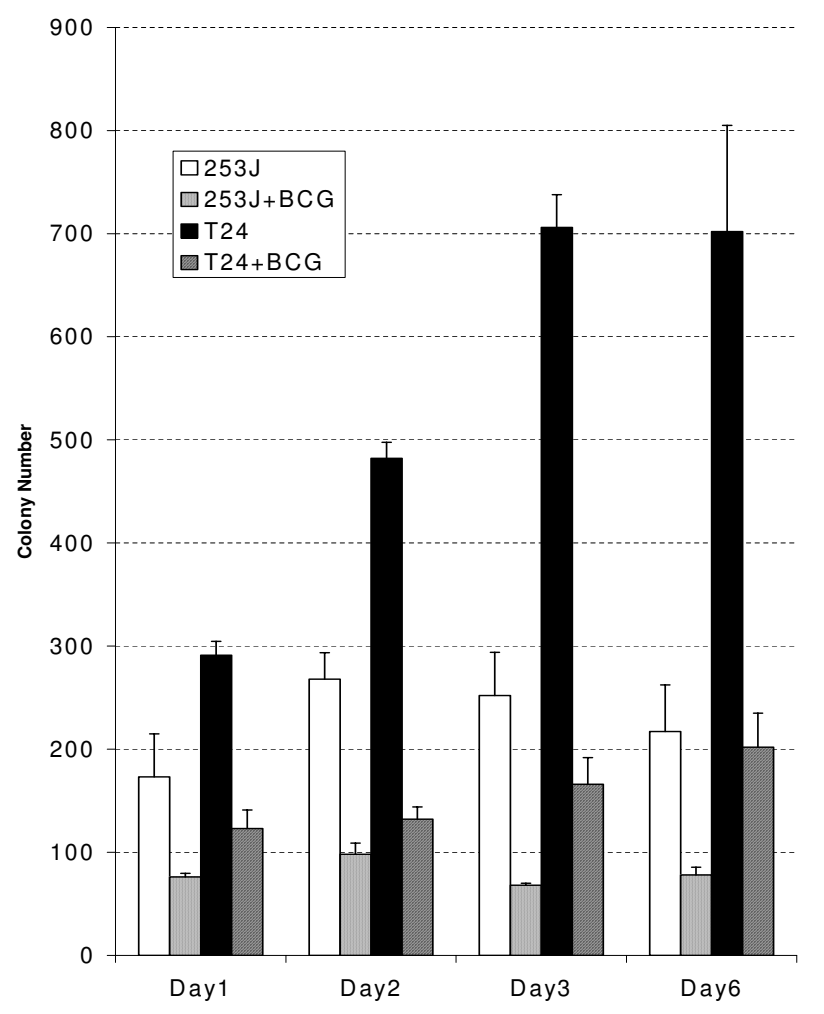

Figure 2

BCG decreases the proliferation of human urothelial carcinoma cell lines as measured by Colony Forming assay. Exposure of either 253j or T24 cells to BCG results in a time dependent decrease in viable cell number as measured by colony outgrowth. The day represents the duration of exposure to BCG.

fraction in BCG treated cells represented $60 \%$ and $65 \%$ of the control groups in 253J and T24 cells respectively.

\section{Antibody mediated $\alpha 5 \beta$ I integrin cross-linking induces cell} cycle arrest at the GI/S interface

Figure 6 demonstrates the effect of antibody mediated $\alpha 5 \beta 1$ cross-linking on cell cycle compartmentalization in 253J and T24 cells. Following cross-linking, the percentage of cells in Go/G1 increased $29 \%$ and $48 \%$ in the respective cell lines. The increase in $\mathrm{G}$ phase population was mirrored by a decrease in the percent of cells in $S$ phase. The S phase cell fraction in cross-linked cells represented $71 \%$ and $60 \%$ of the control groups in $253 \mathrm{~J}$ and T24 cells respectively. 
$3 \mathrm{a}$

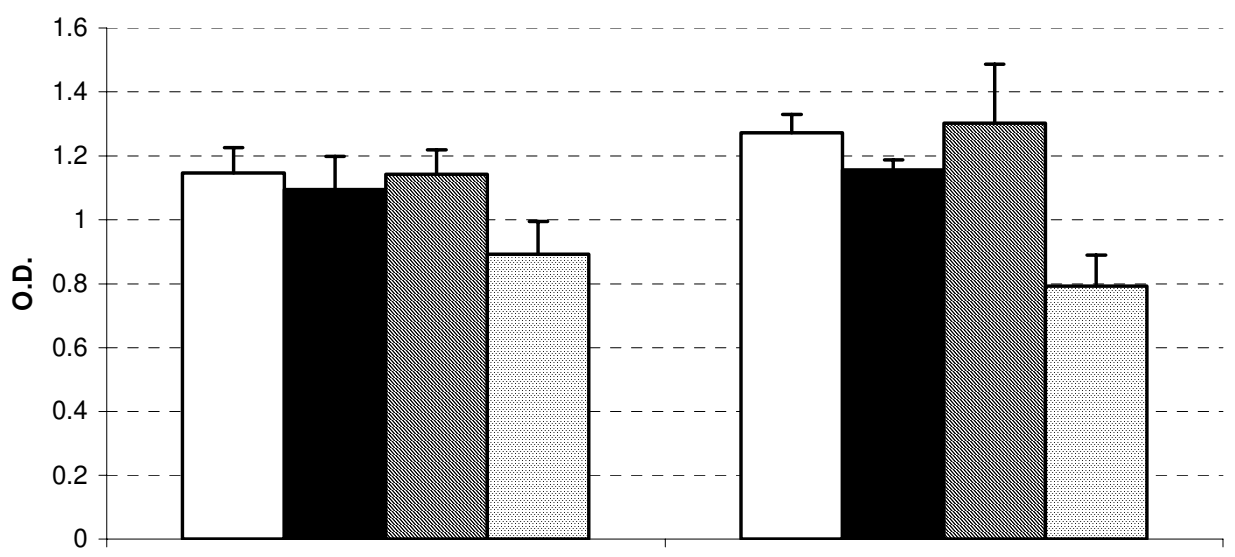

day 3

day 6

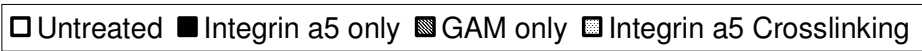

$3 b$

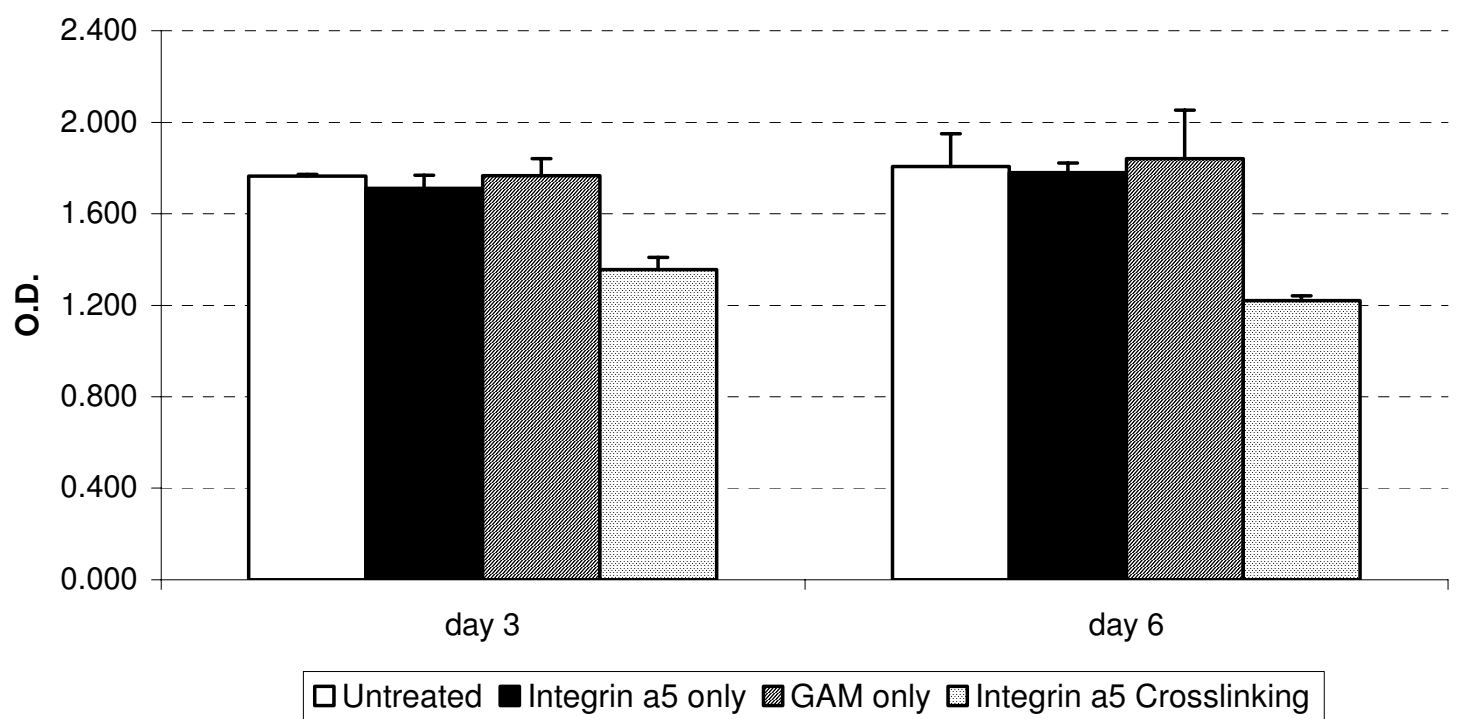

Figure 3

Antibody mediated cross-linking of $\mathrm{a} 5 \mathrm{bl}$ integrin decreases the proliferation of human urothelial carcinoma cell lines as measured by the MTT assay. Results are shown for a 5 cross-linking in both $253 \mathrm{~J}$ cells (figure $3 \mathrm{a}$ ) and T24 cells (Figure 3b). Identical results were obtained when cross-linking was performed using antibodies to bl (data not shown). 


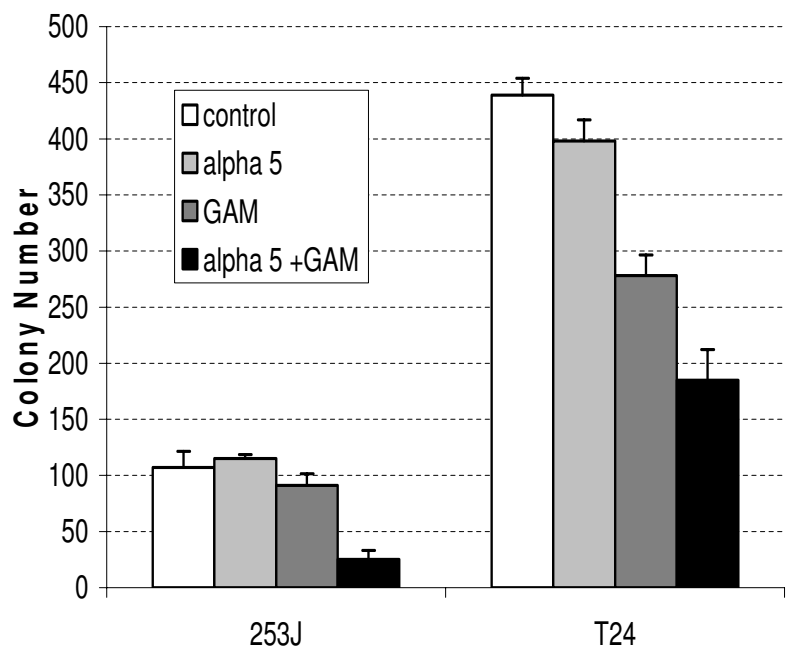

Figure 4

Antibody mediated cross-linking of $\alpha 5 \beta$ I integrin decreases the proliferation of human urothelial carcinoma cell lines as measured by Colony Forming assay.
Peptide blockade of integrin fibronectin binding sites using RGDS reverses the effect of BCG on proliferation and cell cycle arrest

BCG attaches to the cell surface via a fibronectin bridge linking mycobacterial receptors to cell surface integrins.[12-14] Mycobacterial binding of multiple integrin bound fibronectin molecules can affect crosslinkage of integrin receptors.[8] Blocking the ability of FN to bind to either cellular or mycobacterial receptors precludes BCG attachment to the cell surface. $[8,14]$ This series of experiments employed a competitive inhibitor of FN binding to integrins (RGDS) to assess the effect of inhibiting BCG binding to integrin receptors on the biologic response to BCG. While RGDS competitively inhibits the ability of FN to function as an opsonin for BCG binding (effectively inhibiting BCG/integrin interaction), prior studies have demonstrated that RGDS does not effect integrin mediated signaling initiated in response to antibody mediated cross linking of $\alpha 5 \beta 1$.[8] 253J cells were pre-incubated with RGDS or the control (non-blocking) peptide RGES for 1 hour prior to BCG exposure. The MTT and flow cytometric assays were then carried out as described above. Controls included each peptide alone, BCG alone, and untreated cells. In the MTT assay 2 concentrations of both the blocking and control peptides were employed (100 or $250 \mathrm{ug} / \mathrm{ml}$ ). The $250 \mathrm{ug} / \mathrm{ml}$ concentration was used in the flow cytometry assay.

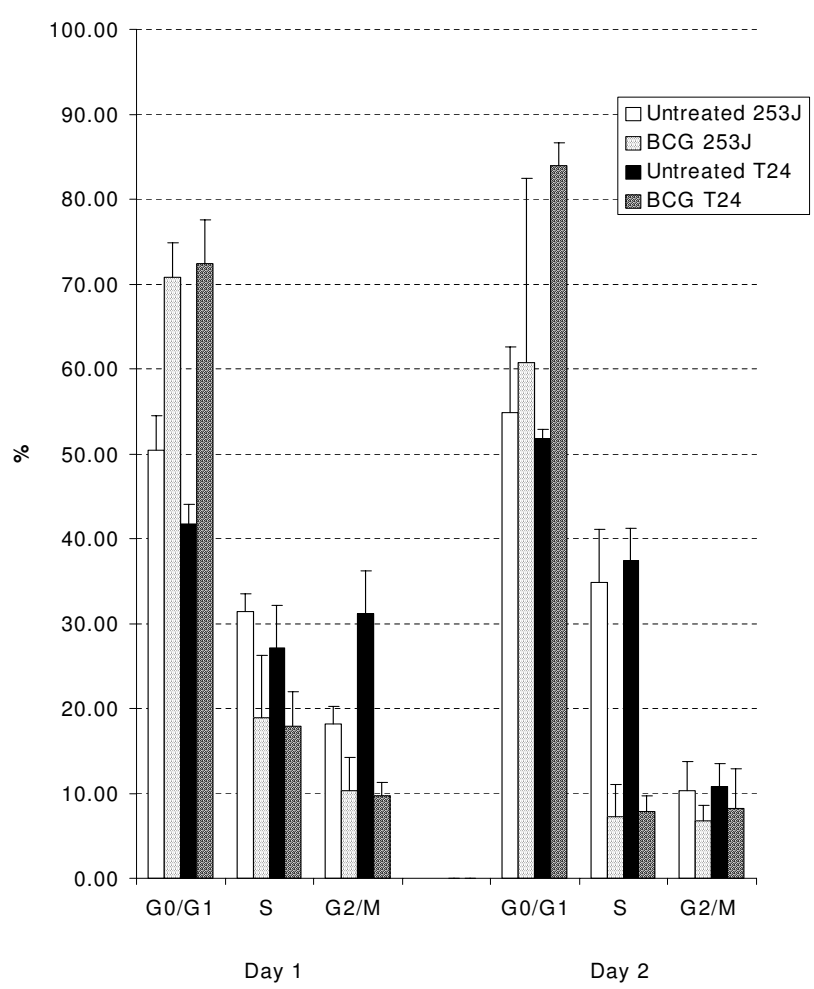

\section{Figure 5}

Human urothelial carcinoma cells exposed to BCG undergo cell cycle arrest at the GI/S interface. Both 253J and T24 cell lines increased the percentage of cells in GI, with a concomitant decrease in the $S$ phase fraction, following $B C G$ exposure.

Figure 7 demonstrates the effect of integrin blockade on the anti-proliferative effect of BCG as measured by MTT assay. RGDS reduced the BCG effect in a "dose-response" manner with a maximal 4 fold inhibition at the $250 \mathrm{ug} /$ ml concentration. RGES had no effect. In the flow cytometric assay, RGDS inhibited G1 arrest. The BCG induced increase in the G1 fraction was reduced by $60 \%$ in RGDS treated cells. RGES pretreatment had no effect on G1 or S phase fraction compared to controls (Figure 8).

\section{BCG does not induce an apoptotic response in urothelial carcinoma cell lines}

A series of experiments were conducted to determine if BCG exposure induced apoptosis in either the 253J or T24 cell lines. Gel electrophoresis of cellular DNA obtained at intervals following BCG exposure failed to demonstrate the laddering associated with apoptosis. Flow cytometry for the apoptotic pathway enzyme caspase 3 failed to 
$6 \mathrm{a}$

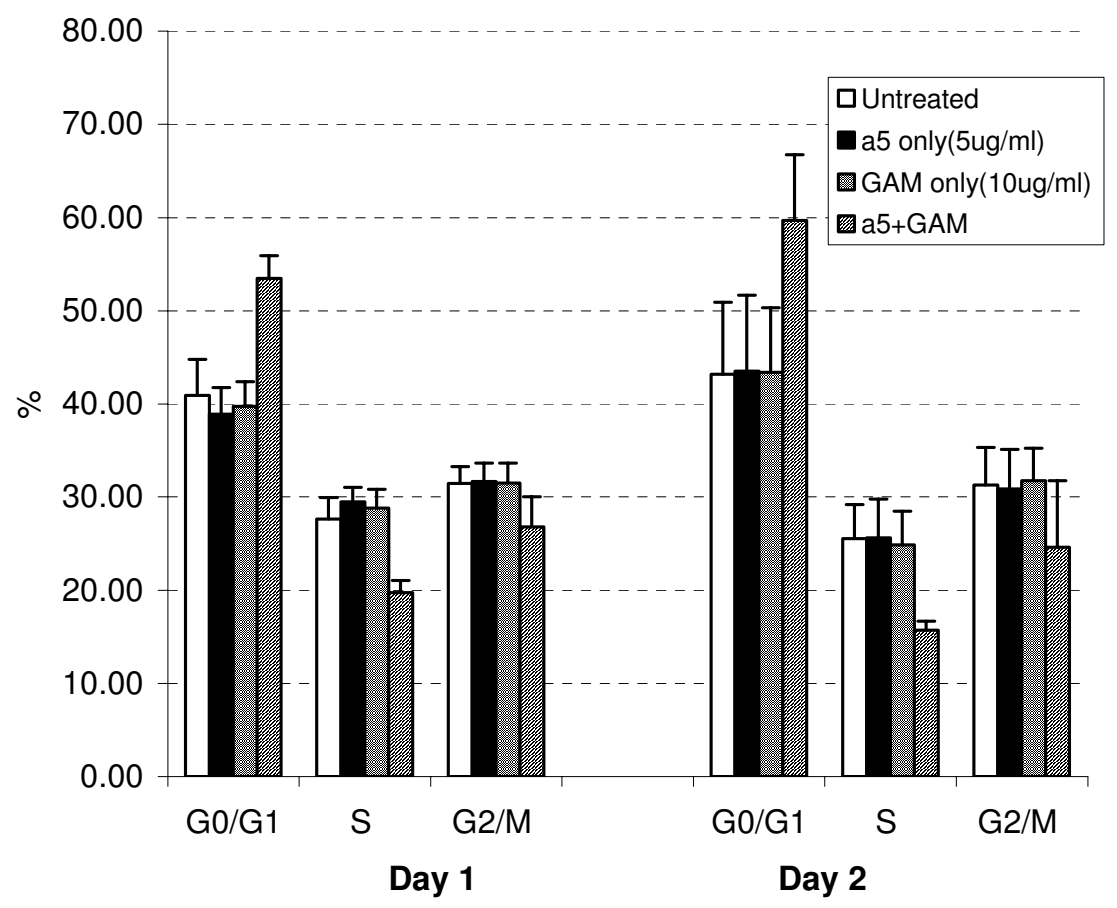

$6 \mathrm{~b}$

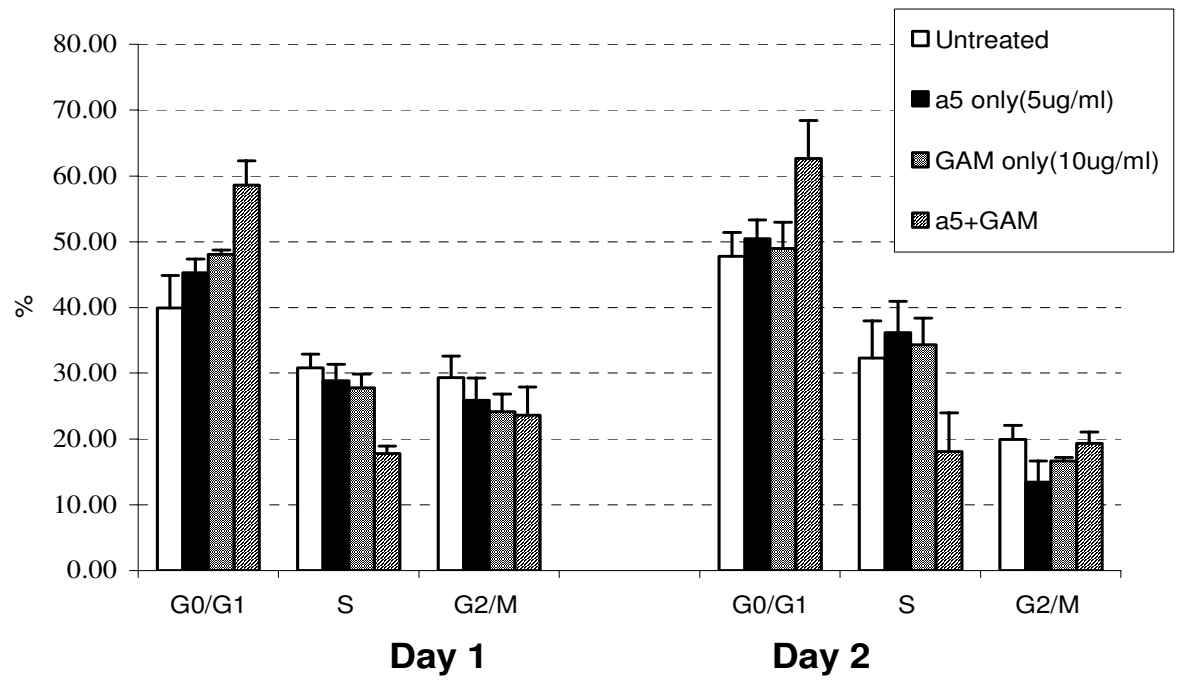

Figure 6

6a and 6b. Cell cycle compartmentalization in 253j (Figure 6a) and T24 (Figure 6b) cells following antibody mediated cross-linking of $\alpha 5 \beta \mathrm{I}$ integrin. Similar to the effect observed in response to BCG, antibody mediated cross-linking resulted in an accumulation of cells in G0-GI with a concomitant decrease in the S-phase fraction. 


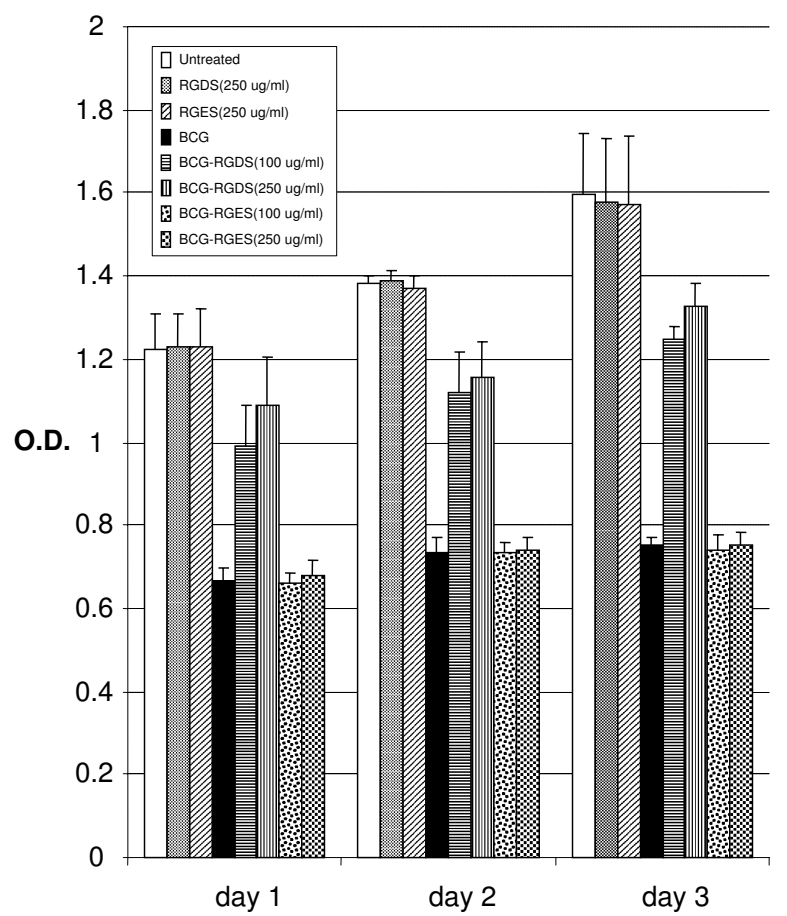

Figure 7

The effect of BCG on 253J Cellular Proliferation as measured by MTT assay. Peptide mediate integrin blockade (RGDS) reversed the anti-proliferative effect of BCG in a doseresponse manner. The control peptide RGES had no effect.

demonstrate activation of this enzyme in response to BCG. (Data not shown)

\section{Discussion}

The anti-tumor effect of BCG is well established. Clinical experience, the results of animal models, as well as in vitro experiments provide data in clear support of this effect. While an anti-tumor effect of BCG is certain, the mechanism through which this occurs is less clear. In vivo animal models of BCG's anti-tumor effect suggest a critical role for a cell mediated immune response. At the same time, in vitro studies using human urothelial cell lines identify a direct effect of BCG. The relative contribution of these two possible mechanisms to BCG's clinical antitumor activity is unknown.

A number of studies suggest that a direct anti-tumor effect is at least in part responsible for BCG's activity. Work by Pryor, Ciao, and Sasaki all have reported a direct anti-proliferative effect of BCG. $[5,6,15]$ Liu et al demonstrated that BCG, as a consequence of its interaction with cell surface bound fibronectin, abrogates invasion and motility

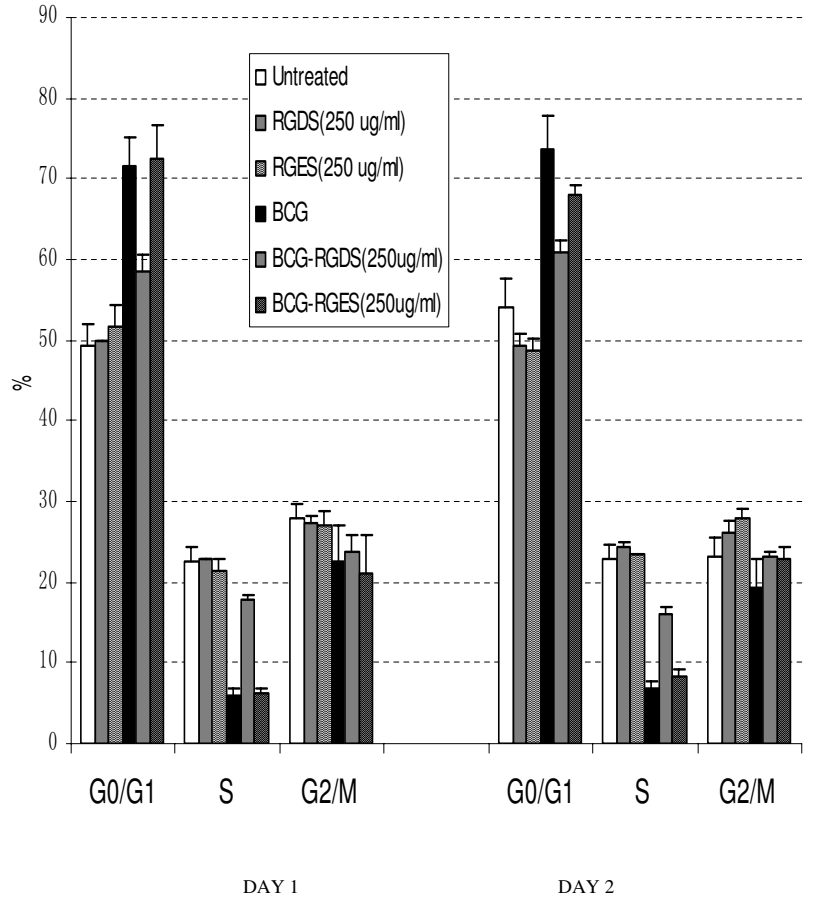

Figure 8

The effect of BCG on 253j cell cycle compartmentalization as measured by flow cytometry. Peptide mediate integrin blockade (RGDS) reversed the GI cell cycle arrest effect of BCG. The control peptide RGES had no effect.

of urothelial carcinoma cell lines.[7] Cellular internalization of BCG, with resultant alterations in reactive oxygen species and nitric oxide, has been proposed as a mechanism contributing to direct BCG mediated cytotoxicity. $[16,17]$

Fibronectin functions as an opsonin, linking BCG to cell surface fibronectin receptors of which $\alpha 5 \beta 1$ integrin is the predominate FN receptor on urothelial cells. This linkage is a requisite step for BCG's antitumor activity.[14] Rather than constituting a passive interaction, our prior reports have shown that FN mediated BCG adherence to the urothelial carcinoma surface has a pharmacogenetic effect as exemplified by transactivation of IL-6.[9] This effect is mediated through signal transduction pathways involving $\mathrm{NF}-\mathrm{KB}$ and AP-1. BCG induced signaling and gene transactivation pathways are identical to those observed in response to antibody mediated cross linking of $\alpha 5 \beta 1$.[8] Strategies that prevent the ability of FN to function as an opsonin, including competitive inhibition of FN receptors using RGDS and simultaneous saturation of mycobacterial and cell surface FN receptors using excess exogenous $\mathrm{FN}$, inhibit the signaling and transactivation responses to 
BCG. $[8,18]$ The current report moves beyond the details of the signaling pathway to examine the biologic effect of BCG induced signaling on a tumor biologic end point with clear treatment relevance.

Consistent with what has been reported by others, our results demonstrate that BCG exerts a direct anti-proliferative effect on human urothelial carcinoma cell lines. The observed anti-proliferative effect does not appear to occur as a consequence of apoptosis. To our knowledge this report is the first to identify cell cycle arrest at the G1/S interface as a mechanism by which BCG exerts an antiproliferative effect. As was the case for BCG induced signaling and gene transactivation, this effect was reproduced using antibody mediated cross-linking of $\alpha 5 \beta 1$ integrin. Elimination of the opsonin function of fibronectin using the peptide competitive inhibitor RGDS, effectively blocking the ability of BCG to bind integrin receptors, reversed the biologic effects of BCG. These findings, together with the results of prior studies, demonstrate that a portion of the biologic response to BCG occurs as a consequence of FN mediated binding of BCG to integrin receptors present on the urothelial cell surface. The failure of simple integrin ligation to simulate the BCG response, the ability of antibody mediated crosslinking of $\alpha 5 \beta 1$ integrin to duplicate the BCG response, the central role of FN in the biologic response to $B C G$, together with the predominance of $\alpha 5 \beta 1$ as the principal $\mathrm{FN}$ binding integrin on urothelial cells, strongly supports a model in which the biologic response of the tumor cell to BCG occurs as a consequence of BCG crosslinking of $\alpha 5 \beta 1$ integrin receptors.

The results of this study have direct clinical relevance. The demonstration that BCG has a direct anti-tumor effect opens this pathway for potential manipulation to improve treatment outcome. This is important given the fact that $30 \%$ of patients are BCG refractory, and that the long-term durability of response to BCG is limited. Finally, and equally important, the dissection of the pathway through which BCG exerts an anti-tumor effect will allow us to move further towards our ultimate goal of eliminating the need to expose patients to the risk of a viable biologic organism and perhaps allow the development of less toxic equally effective treatment approaches.

\section{Conclusion}

BCG, as a consequence of integrin cross-linking, exerts direct anti-tumor effect against human urothelial carcinoma cell lines. Cell cycle arrest at the G1/S interface, rather than apoptosis, is a mechanism contributing to BCG's anti-proliferative effect. Additional studies will be required to define the molecular pathways that contribute to this response.

\section{Competing interests}

The author(s) declare that they have no competing interests.

\section{Authors' contributions}

FC carried out the flow cytometric experiments for cell cycle arrest and apoptosis and participated in drafting the manuscript. GZ performed the cell viability and colony forming assays and aided in drafting the manuscript. YI developed the protocols for flow cytometric experiments, aided in the design of the studies and drafted the manuscript. WAS conceived of the study, participated in its design and coordination, and drafted the manuscript. All authors read and approved the final manuscript.

\section{Acknowledgements}

This work was supported by a grant from the Department of Veterans Affairs and the Milwaukee Veterans Affairs Medical Center.

\section{References}

I. Malkowicz SB: Intravesical therapy for superficial bladder cancer. Semin Urol Oncol 2000, 18(4):280-8.

2. Bohle A, Jocham D, Bock PR: Intravesical bacillus CalmetteGuerin versus mitomycin $C$ for superficial bladder cancer: a formal meta-analysis of comparative studies on recurrence and toxicity. J Urol 2003, I69(I):90-5.

3. Sylvester RJ, van der MEIJDEN AP, Lamm DL: Intravesical bacillus Calmette-Guerin reduces the risk of progression in patients with superficial bladder cancer: a meta-analysis of the published results of randomized clinical trials. J Urol 2002, 168(5): 1964-70.

4. Bohle A, Brandau S: Immune mechanisms in bacillus CalmetteGuerin immunotherapy for superficial bladder cancer. J Urol 2003, I 70(3):964-9.

5. Pryor K, Stricker P, Russell P, et al.: Antiproliferative effects of bacillus Calmette-Guerin and interferon alpha $2 b$ on human bladder cancer cells in vitro. Cancer Immunol Immunother 1995, 4I(5):309-I6.

6. Seow SW, Rahmat JN, Mohamed AA, et al.: Lactobacillus species is more cytotoxic to human bladder cancer cells than Mycobacterium Bovis (bacillus Calmette-Guerin). J Urol 2002, 168(5):2236-9.

7. Liu BC, Redwood SM, Weiss RE, et al: Bacillus Calmette-Guerin abrogates in vitro invasion and motility of human bladder tumor cells via fibronectin interaction. J Urol 1992, I48(3):900-5.

8. Chen F, Zhang G, Iwamoto Y, See WA: Bacillus Calmette-Guerin initiates intracellular signaling in a transitional carcinoma cell line by cross-linking $\alpha 5 \beta I$ integrin. J Urol 2003, I70(2 Pt I):605-10.

9. Chen F-H, Crist SA, Zhang G-1: Interleukin-6 production by human bladder tumor cell lines is upregulated by BCG through NF-kb and AP-I via an immediate early pathway. J Urol 2002, 168:786-797.

10. Mosmann T: Rapid colorimetric assay for cellular growth and survival: application to proliferation and cytotoxicity assays. I Immunol Methods 1983, 65:55-63.

II. Schultz DR, Harrington WJ Jr: Apoptosis: programmed cell death at a molecular level. Semin Arthritis Rheum 2003, 32(6):345-69.

12. Cheng DL, Shu WP, Choi JC, Margolis EJ, Droller MJ, Liu BC: Bacillus Calmette-Guerin interacts with the carboxyl-terminal heparin-binding domain of fibronectin: implications for BCG-mediated anti-tumor activity. J Urol 1994, I52(4): $1275-80$.

13. Zhao W, Schorey JS, Bong-Mastek M, Ritchey J, Brown EJ, Ratliff TL: Role of a bacillus Calmette-Guerin fibronectin attachment protein in BCG-induced anti-tumor activity. Int J Cancer 2000, 86(I):83-8. 
14. Kavoussi LR, Brown EJ, Ritchey JK, Ratliff TL: Fibronectin-mediated Calmette-Guerin bacillus attachment to murine bladder mucosa. Requirement for the expression of an antitumor response. J Clin Invest 1990, 85(I):62-7.

15. Sasaki A, Kudoh S, Mori K, et al.: Are BCG effects against urinary bladder carcinoma cell line T24 correlated with apoptosis in vitro. Urologia Internationalis 1997, 59(3): |42-8.

16. Pook SH, Esuvaranathan K, Mahendran R: $\mathbf{N}$-acetylcysteine augments the cellular redox changes and cytotoxic activity of internalized mycobacterium bovis in human bladder cancer cells. J Urol 2002, 168(2):780-5.

17. Jansson OT, Morcos E, Brundin L, Lundberg JO, Adolfsson J, Soderhall $M$, Wiklund NP: The role of nitric oxide in bacillus CalmetteGuerin mediated anti-tumour effects in human bladder cancer. Br J Cancer 1998, 78(5):588-92.

18. Zhang GJ, Chen FH, Xu Y, Cao Y, Crist S, McKerrow A, Iwamoto Y, See WA: Autocrine overexpression of fibronectin by human transitional carcinoma cells impairs BCG adherence and signaling. J Urol 2004, I 72(4): I496-1500.

\section{Pre-publication history}

The pre-publication history for this paper can be accessed here:

http://www.biomedcentral.com/1471-2490/5/8/prepub

Publish with Biomed Central and every scientist can read your work free of charge

"BioMed Central will be the most significant development for disseminating the results of biomedical research in our lifetime. "

Sir Paul Nurse, Cancer Research UK

Your research papers will be:

- available free of charge to the entire biomedical community

- peer reviewed and published immediately upon acceptance

- cited in PubMed and archived on PubMed Central

- yours - you keep the copyright 